Os Estudos de Tendências Enquanto Disciplina Acadêmica Trends Studies as an Academic Subject

Suzana Amarante de Mendonça Cohen Mestre, Universidade de Lisboa suzanacohen@gmail.com 


\title{
Os Estudos de Tendências Enquanto Disciplina Acadêmica
}

Trends Studies as an Academic Subject

Suzana Amarante de Mendonça Cohen

\section{Resumo}

Esta é uma entrevista com o Prof. Dr. Nelson Pinheiro Gomes, da Universidade de Lisboa, sobre os Estudos de Tendências enquanto área acadêmica. Trata-se de uma nova disciplina, que encontra-se em fase de sedimentação. O professor discorre sobre o seu percurso acadêmico, da moda até chegar ao estudo de tendências socioculturais, assim como sobre o que busca nesta disciplina em termos de práticas internacionais e consolidação da área. $O$ entrevistado dá sua opinião sobre o nascimento de tendências, a importância da análise do DNA Cultural de uma sociedade no que diz respeito às tendências e a aplicação prática desta área de estudos. Por fim, dá um parecer sobre a posição de Lisboa no contexto atual dos Estudos de Tendências.

Palavras-chave: Estudo de Tendências, Tendências Culturais, Gestão de Cultura.

\begin{abstract}
This is an interview with Prof. Dr. Nelson Pinheiro Gomes, from the University of Lisbon. The approach is on Trends Studies as an academic area, which is a new discipline, in process of sedimentation. The professor discusses his academic path, going from fashion to the study of sociocultural trends, as well as what he seeks in this discipline in terms of international practices and consolidation of the area. The interviewee gives his opinion about the birth of trends, the importance of the analysis of the Cultural DNA of a society and the practical application of this area of studies. Finally, he gives his opinion about the moment Lisbon goes through and the context of Trend Studies.
\end{abstract}

Keywords: Trends Studies, Cultural Trends, Cultural Management. 


\section{Apresentação}

Nesta entrevista abordaremos os Estudos de Tendências enquanto área acadêmica, buscando desvendar o que está por trás dessa nova disciplina. A área é transdisciplinar e articula disciplinas das Humanidades, Ciências Sociais e Ciências Empresariais, e de maneira mais específica a comunicação, o marketing e a sociologia. A proposta de elevar os Estudos de Tendências a área acadêmica surgiu como uma resposta à necessidade de organizar e unificar o que já existia em termos de estudos - que, em grande parte, eram voltados a questões de mercado conferindo um caráter científico e metodológico confiável para a aplicação acadêmica.

Os Estudos de Tendências vão além da esfera da moda, sua vertente mais conhecida, e se aplica a mentalidades de uma sociedade, abrangendo questões de comportamento e consumo, tecnologia, literatura, economia, dentre outras. Os Estudos da Cultura têm sido uma área de acesso aos Estudos de Tendências, que tem como foco buscar manifestações visíveis e invisíveis que impactam a sociedade e a cultura.

Nosso entrevistado é Nelson Pinheiro Gomes (figura 1), Professor Auxiliar no Programa em Cultura e Comunicação da Faculdade de Letras da Universidade de Lisboa. Além da atividade docente, Gomes tem desenvolvido pesquisa na área da Gestão da Cultura, voltada especificamente para o estudo de tendências e para o branding cultural. Possui um Doutorado e um Pós-doutorado na Especialidade de Cultura e Comunicação, ambos pela Universidade de Lisboa; Mestrado em Ciências da Cultura - Comunicação e Cultura; MBA em Gestão de Empresas; Licenciatura em História. É pesquisador do grupo English Studies: Culture (RG 2) do Centro de Estudos da Anglísticos da Universidade de Lisboa (CEAUL).

Relevante ressaltar que Lisboa, cidade onde o professor reside e trabalha, vive hoje um momento de efervescência cultural, atraindo os holofotes da classe criativa e empreendedora. Resta saber se a posição privilegiada da cidade no contexto criativo colabora no desenvolvimento dessa área de estudos em Portugal. 


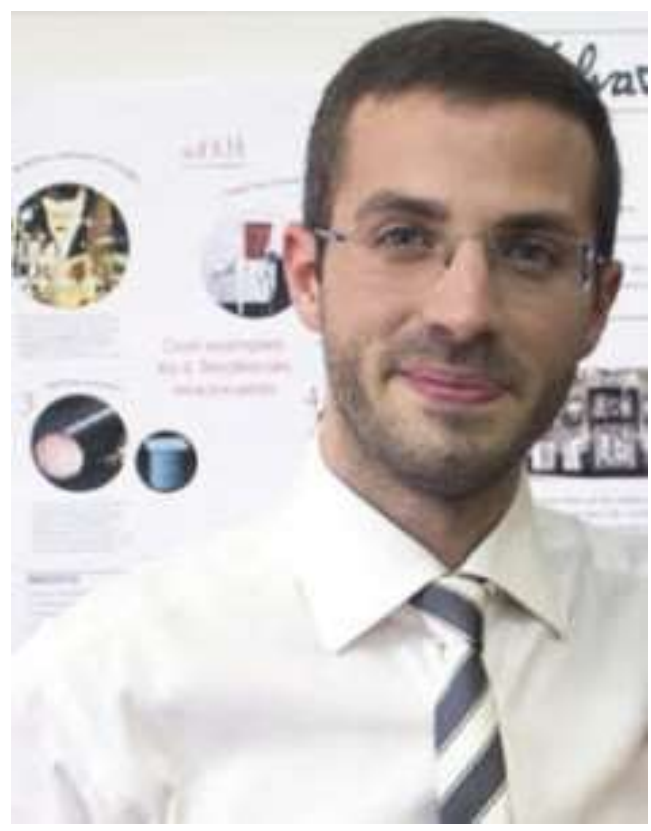

Figura 1: Nelson Pinheiro Gomes. (Arquivo Pessoal, 2017)

\section{Entrevista}

\section{a. $O$ que te motivou a estudar tendências?}

Um dos temas que sempre me fascinou foi a moda. Procurei aprofundar as disciplinas da teoria e da cultura da moda, de tal forma que me parecia clara a complexidade do sistema social e cultural por detrás do fenômeno. Depois da cultura da moda, tive contato com o campo do estudo das tendências socioculturais. Uma vez que as articulações com a área da moda eram muitas, o estudo de outras tipologias de tendências parecia um caminho natural com grande potencial de pesquisa.

b. Qual a sua motivação para se empenhar na consolidação dos Estudos de Tendências em uma disciplina acadêmica?

O desenvolvimento de uma nova disciplina obriga à investigação fundamental e, neste caso, aplicada. Importa ter em consideração as melhores práticas internacionais para se conseguir propor uma visão unificada sobre a área. $\mathrm{O}$ reconhecimento dos Estudos de Tendências como uma disciplina acadêmica potencializa a investigação e o seu próprio desenvolvimento.

c. Qual é a temática dos Estudos de Tendências que mais Ihe interessa? 
Compreender dinâmicas por detrás das tendências de mentalidade são, para mim, o melhor e maior desafio. Nós conseguimos observar e analisar as manifestações visíveis das tendências. Contudo, importa abordar a construção das mentalidades e os vários processos, muitas vezes invisíveis, que permitem a formação e disseminação de um padrão de mentalidade.

d. Os Estudos de Tendências são uma área transdisciplinar que articula disciplinas diversas, como as Humanidades, as Ciências Sociais e as Ciências Empresariais, e de maneira mais específica a comunicação, o marketing e a sociologia. Tendo isso em mente, quais são as suas principais referências?

Como os Estudos de Tendências ainda não são uma área unificada, há uma grande dispersão de perspectivas e de conceitos, já para não falar de abordagens. Tendo em conta a minha formação, exploro principalmente os conceitos dos Estudos de Cultura e abordo com maior interesse as problemáticas da Gestão da Cultura. Neste sentido, importa sublinhar a importância de autores como Grant McCracken (2010). Dentro da própria temática de tendências, há vários autores que devemos considerar. Para enunciar apenas alguns, sublinho os trabalhos de Henrik Vejlgaard (2008), William Higham (2009), Martin Raymond (2010), Peter Gloor e Scott Cooper (2007).

e. O trabalho de análise de tendências é mais complexo do que o senso comum imagina, envolvendo uma análise cultural profunda, contextos, cenários, entre outros elementos. Qual é a importância de se estudar o DNA Cultural de uma sociedade no contexto das tendências?

Ao compreender as várias dinâmicas culturais e as tendências de mentalidade, torna-se mais fácil delinear estratégias de ação a nível empresarial, e outros. Se conseguimos compreender as mudanças na sociedade, então podemos adaptar-nos mais facilmente e gerar maior valor.

\section{f. Como nasce uma tendência? O processo é evolutivo ou disruptivo?}

Essa é uma questão complexa e de difícil resposta. Por um lado, as tendências surgem como uma evolução e articulação de vários contextos e mentalidades anteriores. Todavia, muitas vezes manifestam-se de forma 
aparentemente disruptiva. Assim sendo, talvez tenhamos de considerar as duas perspectivas.

g. Como você vê os Estudos de Tendências do ponto de vista prático / profissional?

Os Estudos de Tendências são uma disciplina que facilmente se articula com várias práticas profissionais. Eles adicionam às competências base de cada profissional a capacidade de identificar padrões de comportamento emergentes, 0 que pode ser muito útil ao nível do marketing, da gestão, do design, entre outras áreas.

h. Lisboa encontra-se num momento de efervescência criativa. Qual é a sua visão sobre a cidade e a sua relação com os Estudos de Tendências? Concorda que a cidade está vivendo uma momento de transformação e que isso a coloca numa posição privilegiada para a pesquisa na área de tendências?

Do ponto de vista acadêmico, importa ter os recursos e os especialistas necessários para desenvolver pesquisa e produzir resultados. Lisboa é uma excelente cidade para estudar tendências e observar os seus sinais. As alterações que a cidade está sofrendo obrigam a desenvolver uma nova perspectiva sobre as suas dinâmicas e representam uma oportunidade importante para observar mudanças no espaço urbano.

\section{Referências}

GOMES, N. P. Trends Management applied to branding and cultural management. In: Revista Logo. Vol5, no 1, 2016.

GLOOR, P.; COOPER, S. Coolhunting: Chasing down the next big thing. New York: Little Brown, 2007.

HIGHAM, W. The Next Big Thing. London: Kogan Page, 2009.

MCCRACKEN, G. Chief Culture Officer: How to Create a living, breathing corporation. New York: Basic Books, 2009.

RAYMOND, M. The Trend Forecaster's Handbook. London: Laurence King, 2010.

VEJLGAARD, H. Anatomy of a Trend. New York: McGraw-Hill, 2008. 
Recebido em: 24/05/2017

Aprovado em: 31/05/2017

Endereço do autor:

Suzana Amarante de Mendonça Cohen

Universidade de Lisboa. Faculdade de Letras

Alameda da Universidade

1600-214. Lisboa, Portugal

Telefone: +351217920000 